\title{
Recognition Memory Correlates of Hippocampal Theta Cells
}

\author{
Sherman P. Wiebe and Ursula V. Stäubli \\ Center for Neural Science, New York University, New York, New York 10003
}

Investigations of hippocampal theta cell activity have typically involved behavioral tasks with modest cognitive demands. Recordings in rats locomoting through space or engaged in simple stimulus discrimination or conditioning have revealed some place specificity and $\mathrm{S}^{+} / \mathrm{S}^{-}$selectivity in addition to the hippocampal EEG theta-related behavioral/motor correlates. However, little data exist regarding theta cell activity during performance of more cognitively demanding, hippocampal-dependent recognition memory tasks. Here, we examined the cognitive firing correlates of theta cells in rats that were performing an olfactory recognition memory task with distinct sample and test phases. Discriminant analysis revealed odor and match/nonmatch memory correlates in theta cell activity comparable in relative magnitude to that of the principal cells. Odor-specific theta cell responses in the sample phase were restricted primarily to CA1 and linked to task performance. In the test recognition phase, match/nonmatch theta cells were found primarily in the CA3 and CA1 fields, most of which exhibited greater activity on correct nonmatch trials in which recognition occurred than on error match trials in which recognition failed. Odor selectivity of the match/ nonmatch signaling was greatest in the dentate gyrus (DG) and CA3 and least in CA1. This inverted pattern of stimulus specificity in the sample versus test phase was similar to that observed in principal cells but with a greater contrast between the CA1 and DG/CA3 fields. Together, these findings suggest that theta cells actively participate in hippocampal recognition memory processing and play a specific role in shaping the cognitive firing properties of the hippocampal principal cells.

Key words: interneurons; theta cells; hippocampus; DNMS; odors; spatial; match/nonmatch discrimination; recognition memory; cognition; dynamic filtering; generalization; dentate gyrus; CA3; CA1; principal cells
The gross behavioral correlates of hippocampal theta interneurons have been known for almost three decades. Ranck's original description of theta cells (Ranck, 1973) focused on activity relating to movement and arousal and the correlation with hippocampal slowwave theta rhythm; hence the name "theta cell." Most recording studies of theta cells since then have involved tasks with minimal cognitive demands, typically with a rat searching for randomly positioned food rewards in an open area or moving through a maze or linear track. In these situations, behavior/motor correlates (Ranck, 1973; O'Keefe and Nadel, 1978) have been observed along with some modest place specificity (McNaughton et al., 1983a; Kubie et al., 1990). A few studies have reported learning-related theta cell firing correlates during simple perceptual discrimination (Christian and Deadwyler, 1986; Eichenbaum et al., 1987) and trace eyeblink conditioning (McEchron and Disterhoft, 1997); however, little data exist describing theta cell activity during performance of cognitively demanding, hippocampaldependent recognition memory tasks. Principal cells, and not theta interneurons, have traditionally been the focus of hippocampal recording studies of recognition memory. Recognition memory tasks such as delayed-nonmatch-to-sample (DNMS) are represented in hippocampal principal cell firing (Deadwyler et al., 1996; Wood et al., 1999) and are sensitive to hippocampal lesions (Wood et al., 1993; Alvarez et al., 1995; Hampson et al., 1999). Therefore, given the prominent role that hippocampal interneurons play in

\footnotetext{
Received July 31, 2000; revised Feb. 22, 2001; accepted Feb. 26, 2001.

We thank Drs. Wendy Suzuki, Hugh T. Blair, Robert Hampson, and Sam Deadwyler for helpful comments on preliminary versions of this manuscript. We thank Joey Scafidi and Mariam Ejaz for technical assistance and help with behavioral training.

Correspondence should be addressed to Sherman P. Wiebe, Plexon Inc., 6500 Greenville Avenue, Suite 730, Dallas, Texas 75206. E-mail: Sherman@ plexoninc.com.
}

Copyright (C) 2001 Society for Neuroscience $\quad 0270-6474 / 01 / 213955-13 \$ 15.00 / 0$ modulating principal cell population activity via feedforward (Buzsaki, 1984) and feedback (Andersen et al., 1963, 1964) inhibition, the following question arises: do hippocampal theta cells, like the principal cells, represent information about nonspatial perceptual variables and higher cognitive and mnemonic functions? And, if so, how do those representations compare with that of the principal cells?

Hippocampal principal cells (pyramidal and dentate granule cells) can be distinguished from theta interneurons in freely moving rats on the basis of their electrophysiological properties. Hippocampal principal cells are known to encode both odors (Wiebe and Stäubli, 1999; Wood et al., 1999) and match/ nonmatch comparisons (Otto and Eichenbaum, 1992; Rolls et al., 1993; Deadwyler et al., 1996; Wood et al., 1999) within the DNMS recognition memory task. Some evidence also exists for differential processing of stimulus events within the hippocampal subfields (Hess et al., 1995; Deadwyler and Hampson, 1998). In a previous report of principal cell activity during olfactory DNMS performance (Wiebe and Stäubli, 1999), an inversely graded distribution of stimulus-specific responses was found across the hippocampal subfields in the sample acquisition phase (maximal in CA1, minimum in DG) compared with the recall phase (maximal in DG, minimum in CA1). To investigate the perceptual and cognitive firing correlates of theta cells and to compare them with that of principal cells, we recorded hippocampal principal cells (Wiebe and Stäubli, 1999) and theta interneurons in the DG, CA3, and CA1 subfields in rats performing an odor-guided DNMS task with distinct sample and test phases.

\section{MATERIALS AND METHODS}

A detailed description of the apparatus, behavioral training protocol, surgery, and recording techniques has been included in a previous study 
of hippocampal principal cell activity during DNMS performance (Wiebe and Stäubli, 1999). Briefly, adult male Long Evans rats (weight at time of surgery, $250-460 \mathrm{gm} ; n=18$; the same rats were used in the companion principal cell paper) were water-deprived for $20-22 \mathrm{hr}$ before DNMS performance but allowed ad libitum food. All animals were trained to stable DNMS performance ( $>85 \%$ correct on $0-5$ sec delays) before and after electrode implantation. The apparatus was a soundattenuating wooden Y-shaped chamber [sample arm, $36 \times 23 \times 59$ (length $\times$ width $\times$ height) cm; test arms, $27 \times 14 \times 59 \mathrm{~cm}$; central area, $33 \times 23 \times 59 \mathrm{~cm}$ ] surrounded by an electrically grounded copper mesh grid. Cylindrical nosepoke ports (diameter, $20 \mathrm{~mm}$ ) and water troughs were located at the end of each arm, and photodetector-LED pairs were located at the entrance to each arm to record behavioral events. A cue light positioned above the sample port was illuminated during the sample and delay phases, and a house light was lit during the test phase. Solenoid valves mounted outside the chamber were used to deliver the odorized air (either Apple Oliffac or Carenko; International Flavors and Fragrances, Inc., New York, NY) at the end of each arm. Odorized airstream concentration and flow rates at the end of each arm were controlled by a flow-dilution olfactometer. Lingering odors were extracted from the chamber by a ceiling fan and vacuum pump. Water rewards $(0.05 \mathrm{ml})$ were delivered using a gravity-feed system through a solenoid valve to troughs located directly below the test-arm nosepoke devices. A high-intensity flashbulb mounted on the ceiling of the chamber signaled error responses. A computer with custom-designed digital input-output interfaces controlled the apparatus.

\section{Behavior}

Animals were trained on the two-odor simultaneous DNMS task, illustrated schematically in Figure $1 A$, as described in Wiebe and Stäubli (1999). Illumination of a cue light above the sample port marked the start of the trial. The first sample nosepoke commenced a $2 \mathrm{sec}$ minimum pre-odor baseline period, after which a nosepoke turned on the odor (either odor A or odor B). After a minimum of $10 \mathrm{sec}$ of odor exposure, a nosepoke terminated the odor and initiated a variable 1-50 sec delay period. After the delay, a sample poke extinguished the cue light, illuminated the ceiling house light, and prompted the delivery of the two odors in the test arms, one odor per arm. The rat exited the sample arm and then simultaneously discriminated the two odors in the center region of the Y maze, just outside the entry point of the test arms. On discrimination of the two odors, the rat selected one of the odors by entering an arm and committing a nosepoke. The test odors (one in each arm) emanated continually from both test arms and could be detected within and just outside the entry point of the arms, regardless of whether a nosepoke was made in the arm. The distance between the test-arm entry point and the infrared beam in the nosepoke device protruding from the end of the test arm was short $(24 \mathrm{~cm}$, approximately the body length of the rat) and was traversed rapidly by the water-deprived rats. The time between arm entry and the nosepoke was an accurate measure of locomotion in the test arms because the time span was short (mean, $0.920 \mathrm{sec}$, on average for each rat) and varied little across trials (SEM, $0.009 \mathrm{sec}$ ). A nosepoke in the nonmatch arm resulted in a $0.05 \mathrm{ml}$ water reward. A match response triggered a high-intensity flash discharge. By definition, then, all nonmatch trials were correct trials, and all match trials were error trials. Three seconds after both correct and error responses, odor delivery to the test ports was terminated, the house light was extinguished, and an intertrial interval of $20 \mathrm{sec}$ was imposed. The identity of the sample odor and location of the match and nonmatch test odors were randomized across trials. Performance diminished linearly as a function of delay from $86 \%$ correct at $0-5$ sec delays to $74 \%$ correct at $45-50 \mathrm{sec}$ delays. Figure $1 B$ shows the mean performance curve per session summed over all rats, with 100-250 trials per session.

Although the rat could correct initial odor/arm selections in the test phase by stopping after entering one arm, backing up, and then entering the other arm, this postselection corrective behavior was observed on a relatively small percentage of trials $(6 \pm 1 \%$ of the trials per session; mean \pm SEM averaged across all rats). This implies that on most trials, the rats made the match/nonmatch decision in the test phase while sampling the two odors simultaneously at the junction between the two test arms, as opposed to selecting one particular odor or arm in the test phase by default and then making a corrective response if necessary. Therefore, the task was performed as "delayed-nonmatch-to-sample" and not using alternative response strategies such as "win-stay/loseshift" involving corrective responses after initial default choices.

The delayed-nonmatch-to-sample task by definition (Suzuki, 1996) is comprised of three phases: (1) sample item presentation, followed by (2) a delay interval, followed by (3) a recognition phase in which one or more test items are presented, with reward resulting from selection of the nonmatch item. Many rat hippocampal recording studies of recognition memory implementing the DNMS paradigm have used the continuous protocol (Otto and Eichenbaum, 1992; Wood et al., 1999) in which only one item is presented in the test phase. Individual stimuli are presented sequentially, one after another, with the animal rewarded for recognizing an item as different from its antecedent. In such a paradigm, stimuli are at once both samples for the following item and test cues for the preceding item, thereby potentially obscuring detection of any phasesensitive coding. In the simultaneous two-item DNMS task used here and by others (Mumby and Pinel, 1994; Deadwyler et al., 1996; Murray and Mishkin, 1998), two items (the match cue and the nonmatch cue) are simultaneously presented to the animal in the test phase and continue to be present until the final behavioral response is executed. In the Deadwyler and Mumby studies, spatial cues and nonspatial, visual cues were used as discriminative stimuli, respectively, with the selection response involving lever presses and displacement of three-dimensional objects. In the present study, odors were used as discriminative stimuli, and the behavioral response was a nosepoke. An advantage of the simultaneous DNMS paradigm that was used here, however, with spatially and temporally distinct sample and test phases, was that comparisons could be made between the response properties of cells to stimuli presented in the acquisition versus recall phase of the task.

\section{Surgery}

After criterion behavioral DNMS performance was reached, animals were surgically implanted with an $8 \times 2$ microwire (diameter, $\sim 45 \mu \mathrm{m}$ ) electrode array (NB Labs, Denison, TX). To help eliminate lowfrequency movement artifacts, the recording signals were subtracted from that of a low-impedance-tip reference microwire positioned just posterior and at the same depth as the array. The rat was anesthetized with sodium pentobarbital $(50 \mathrm{mg} / \mathrm{kg}$, i.p.) and given atropine $(0.1$ $\mathrm{mg} / \mathrm{kg}$, i.p.) to reduce mucous secretions. The center pair of electrodes was positioned at coordinates $4.0 \mathrm{~mm}$ posterior to bregma, 3.3 and 2.8 $\mathrm{mm}$ lateral to midline for CA3 and DG-CA1 placement, respectively. The longitudinal axis of the array was rotated to a $30^{\circ}$ angle from midline, with the anterior end more medial and the posterior end more lateral, to follow the contour of the hippocampus. The array was driven slowly $(\sim 25 \mu \mathrm{m} / \mathrm{min})$ through the brain to a depth of $3.4-4.0 \mathrm{~mm}$ for $\mathrm{CA} 3$ and $2.2-3.2 \mathrm{~mm}$ for CA1. Neural activity from the microwire electrodes was monitored throughout surgery to ensure placement near the hippocampal cell layers. After array placement, the cranium was sealed with bone wax and dental cement. The animal was allowed to recover for 6-7 d before DNMS retraining and recording commenced. The scalp wound was treated periodically with Neosporin antibiotic to prevent infection.

\section{Histology}

At the conclusion of recording, the location of each recording electrode was histologically verified (Fig. $1 C$ ) by passing $40 \mu \mathrm{A}$ current through each microwire and reacting with potassium ferrocyanide to form a Prussian blue stain. A Nissl stain was used to aid the visualization of the cell body layers. All animal care and experimental procedures conformed to National Institutes of Health and Society for Neuroscience guidelines for care and use of experimental animals.

\section{Unit recording technique}

Extracellular action potentials ("spikes") and behavioral responses were digitized and time-stamped for computer processing in relation to successive behavioral events within each DNMS trial. Neuronal activity was digitized at $40 \mathrm{kHz}$ and isolated by time-amplitude window discrimination and template matching using a Multichannel Acquisition Processor system (Plexon, Dallas, TX). Up to four single units could be isolated per microwire (Fig. 1D). Identified spikes were tracked from session to session by waveform and firing characteristics within the task (perievent histograms). To maximize the likelihood that single units were recorded, only waveforms with zero spike counts in the first $1 \mathrm{msec}$ time bin of their interspike interval histogram were included in the analysis. Also, to help ensure that the same neurons were recorded continuously over time, waveforms were required to have stable perievent firing rates across sessions. Although it is possible that the neuronal spikes that were 

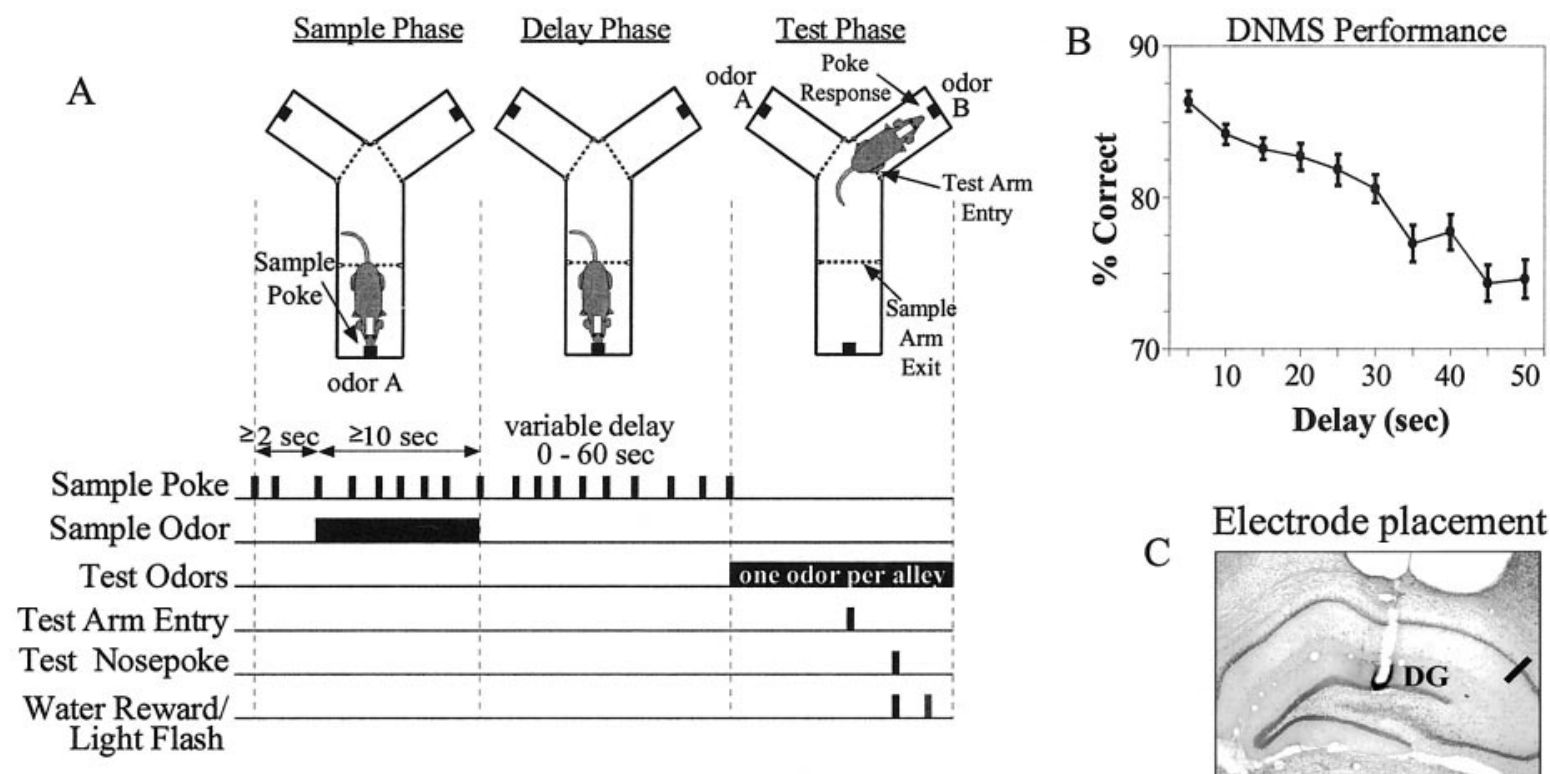

Discrimination of theta interneurons and principal cells

$\mathrm{D}$

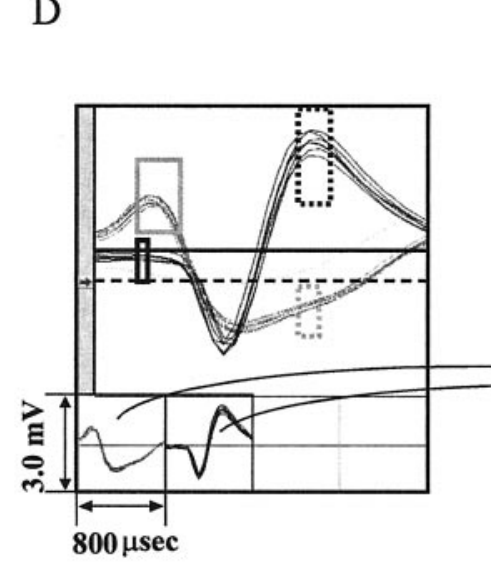

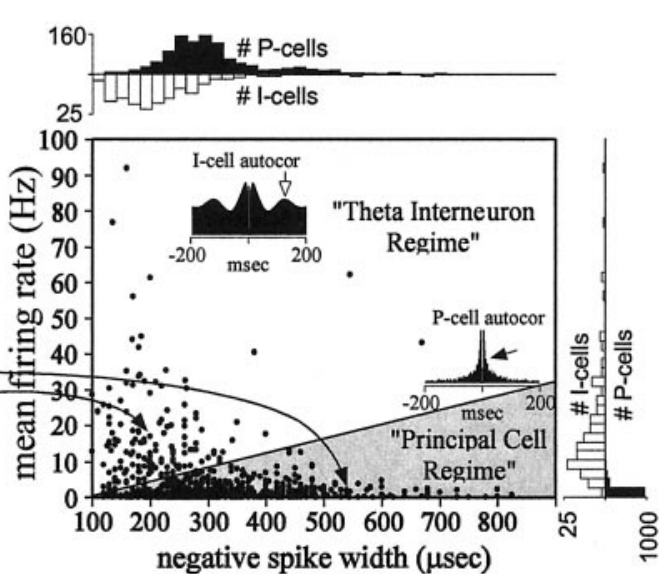
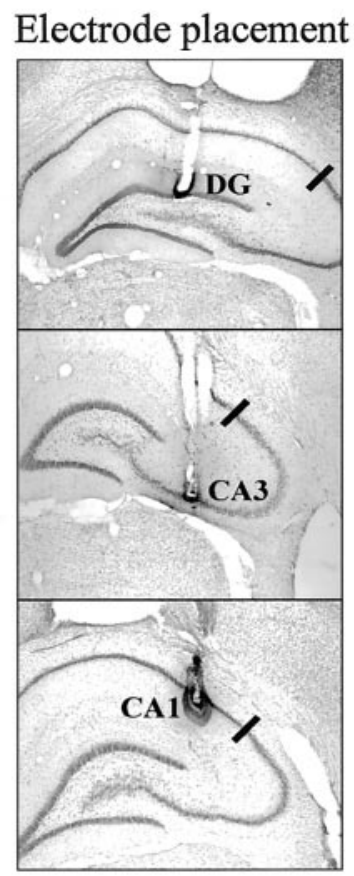

Figure 1. A, Schematic diagram of odor-cued DNMS task. A nosepoke in the sample arm was required to initiate the trial with a minimum 2 sec pre-odor period, after which a sample poke turned on the sample odor (either odor A or B). After 10 sec of odor exposure, a nosepoke turned off the odor and initiated a variable $0-60 \mathrm{sec}$ delay. The first poke after the delay interval turned off a cue light above the sample port, turned on a house light, and prompted the start of the test phase with the delivery of the two odors in the test arms (one per arm). Infrared beams detected the rat's exit from the sample arm, entry into the left and right test arms, and subsequent nosepoke response. A nosepoke in the nonmatch arm resulted in water reinforcement. A match nosepoke triggered the discharge of a light flash. The water reward and light flash reinforcement signals were delayed 1.5 sec on a select number of randomly interspersed trials to determine whether correct/error-selective firing immediately after the test nosepoke was associated with the behavioral execution of the nosepoke or attributable to differential responding to the water reward-light flash. Three seconds after the reinforcement signal, the odors were terminated, the house light was extinguished, and an intertrial interval of $20 \mathrm{sec}$ was imposed. After the intertrial interval, the cue light above the sample port was turned on again, prompting the rat to execute a sample nosepoke to initiate another trial. The identity of the sample odor and location of the match and nonmatch test odors were randomized across trials. $B$, Delay-dependent DNMS performance. Mean \pm SEM percentage of correct trials per recording session (100-250 trials) was averaged over 435 sessions in 18 rats. Trials were grouped in 5 sec intervals and plotted across the 1-50 sec delay period. Note that on the $x$-axis, 5 implies $0-5 \mathrm{sec}, 10 \mathrm{implies} 5-10 \mathrm{sec}$, etc. $C$, Histological verification of microwire placement. Examples of electrode placement in the dentate gyrus (DG, top), CA3 (center), and CA1 (bottom) subfields. The line in each image marks the CA3-CA1 boundary. $D$, Discrimination of theta interneurons and principal cells on the basis of extracellularly recorded physiological parameters. Up to four neurons, principal cells, and/or interneurons could be isolated per microwire channel using time-amplitude window discrimination and template matching. Left, In the example shown, two distinct units with well defined waveform characteristics were discriminated from the same microelectrode. Right, A linear cutoff in firing rate-spike width space was used in conjunction with firing rhythmicity criteria to discriminate principal cells from theta interneurons. Cells with mean firing rates $r$ (in Hertz) and negative-going spike widths $w$ (in microseconds) such that $r<0.04 \cdot w-3.5$ (shaded region) and a peak at 3-5 msec in the autocorrelogram followed by a fast exponential decay ( filled arrowhead) were classified as principal cells and were analyzed previously in Wiebe and Stäubli (1999). Cells with mean firing rates and negative-going spike widths such that $r>0.04 \cdot w-3.5$ and a peak in the $80-200$ msec $(5-12 \mathrm{~Hz})$ range of the autocorrelogram (open arrowhead) were classified as theta interneurons. Marginal distributions of principal cell ( filled histogram) and interneuron (open histogram) spike widths and mean firing rates are shown on top and to the right of the plot, respectively (bin width, $20 \mu \mathrm{sec}, 2.5 \mathrm{~Hz}$ ). The interneuron population (firing rate, mean, $17.4 \mathrm{~Hz}$; SEM, 1.13; min, 2.29; max, 91.93; negative-going spike width, mean, $206 \mu$ sec; SEM, 6; min, 100; $\max , 670 ; n=139)$ was statistically well separated in two-dimensional firing rate-spike width space (MANOVA; $F_{(2,1237)}=817 ; p<$ $10^{-10}$ ) from the principal cell population (firing rate, mean, $1.1 \mathrm{~Hz}$; SEM, 0.05; min, 0.001; max, 13.27; negative-going spike width, mean, $305 \mu$ sec; SEM, 3; min, 120; $\max , 825 ; n=1101)$. P-cells, Principal cells; I-cells, interneurons. 
Table 1. Perievent histogram parameters

\begin{tabular}{|c|c|c|c|c|c|c|c|}
\hline \multirow{2}{*}{$\begin{array}{l}\text { Perievent } \\
\text { histogram name }\end{array}$} & \multirow[b]{2}{*}{ Event } & \multirow{2}{*}{$\begin{array}{l}\text { Bin width } \\
(\mathrm{sec})\end{array}$} & \multirow{2}{*}{$\begin{array}{l}\text { Histogram } \\
\text { limits }(\mathrm{sec})\end{array}$} & \multicolumn{4}{|c|}{ Discriminant analysis factors } \\
\hline & & & & $\mathrm{L} / \mathrm{R}$ & Sample odor A/B & Test odor $\mathrm{A} / \mathrm{B}$ & $\mathrm{C} / \mathrm{E}$ \\
\hline Pre-odor & Sample odor on & 0.25 and 1.0 & {$[-5.0,-1.0]$} & - & - & - & - \\
\hline Odor fast & Sample odor on & 0.25 & {$[-0.5,1.5]$} & - & $\checkmark$ & - & $\checkmark$ \\
\hline Odor slow & Sample odor on & 1.00 & {$[1.5,9.5]$} & - & $\checkmark$ & - & $\checkmark$ \\
\hline Odor off & Sample odor off & 0.25 & {$[-0.5,1.0]$} & - & $\checkmark$ & - & $\checkmark$ \\
\hline Delay & Odor off (delay $\geq 5 \mathrm{sec}$ ) & 1.00 & {$[1.0,5.0]$} & - & $\checkmark$ & - & $\checkmark$ \\
\hline Test entry & Test arm entry & 0.25 & {$[-0.5,0.5]$} & $\checkmark$ & - & $\checkmark$ & $\checkmark$ \\
\hline Pre-poke & Test nosepoke & 0.25 & {$[-1.0,0.0]$} & $\checkmark$ & - & $\checkmark$ & $\checkmark$ \\
\hline Post-poke & Test nosepoke & 0.25 & {$[0.0,3.0]$} & $\checkmark$ & - & $\checkmark$ & $\checkmark$ \\
\hline
\end{tabular}

Sample phase: Odor fast, Odor slow, Odor off. Delay phase: Delay. Test phase: Test entry, Pre-poke, Post-poke.

discriminated on a given microwire may not have isolated single units or consistently identified the same neuron over time (McNaughton et al., 1983b), selecting only waveforms with absolute $1 \mathrm{msec}$ refractory periods, and with constant firing rates and behavioral correlates across recording sessions greatly reduced the probability that different neurons were mistaken as single units (Deadwyler et al., 1996).

\section{Identification of hippocampal principal cells and theta interneurons}

Theta interneurons can be distinguished from principal cells in the hippocampus on the basis of their physiological characteristics. Interneurons in the dentate gyrus (Mizumori et al., 1989; Jung and McNaughton, 1993 ) and CA3/1 fields (Ranck, 1973; Fox and Ranck, 1975, 1981) exhibit high $(>5 \mathrm{~Hz})$ overall mean firing rates modulated at theta rhythm $(5-12$ $\mathrm{Hz}$ ) and have narrow spike widths (most with $<250 \mu$ sec negative-going spike widths); in contrast, granule and pyramidal cells discharge in complex-spike bursts of two to seven spikes at 3-5 msec interspike intervals with low $(<2 \mathrm{~Hz})$ overall mean firing rates and possess large spike widths ( $>250 \mu \mathrm{sec}$ negative-going spike widths). Although mean firing rate alone or spike width alone is insufficient to clearly distinguish the principal cell and theta interneuron populations because of partially overlapping distributions, the two cell groups can be effectively separated if the two parameters are considered together in firing rate-spike width space (Csicsvari et al., 1999). In the present study, up to four individual units could be isolated on each microwire, including at times both principal cells and interneurons on the same wire. A linear cutoff in firing rate-spike width space was used in conjunction with the autocorrelation function to classify the two cell types. Cells with mean firing rates $r$ (in Hertz) and negative-going spike widths $w$ (in microseconds) such that $r<0.04 \cdot w-3.5$ and a peak at $3-5 \mathrm{msec}$ in the autocorrelogram followed by a fast exponential decay (i.e., complexspike activity) were classified as principal cells. Cells with mean firing rates and negative-going spike widths such that $r>0.04 \cdot w-3.5$ and a prominent peak in the $80-200 \mathrm{msec}$ range $(5-12 \mathrm{~Hz})$ of the autocorrelogram were classified as theta interneurons. The two populations of cells (Fig. $1 D$ ) were separated reasonably well in firing rate-spike width space by the linear cutoff method, as measured by multivariate ANOVA $\left(F_{(2,1237)}=817.29 ; p<10^{-10}\right)$. The firing correlates of the theta interneurons (firing rate, $17.4 \pm 1.13 \mathrm{~Hz}$, mean $\pm \mathrm{SEM}$; negativegoing spike width, $206 \pm 6 \mu \mathrm{sec} ; n=139)$ were compared with that of the complex-spike principal cells (firing rate, $1.1 \pm 0.05 \mathrm{~Hz}$; negativegoing spike width, $305 \pm 3 \mu \mathrm{sec} ; n=1101)$ reported in Wiebe and Stäubli (1999).

\section{Analysis}

Event-responsive activity. Perievent histograms were generated for each cell around each DNMS event. The associated event, bin width, histogram boundary limits, and grouping factors for each perievent histogram are shown in Table 1. The responsivity of cells to events in the sample, delay, and test phase was determined by comparing the firing rate within each perievent histogram with its appropriate baseline period. For perievent histograms in the test phase, in which the rat's position was different for each event, the baseline used was mean firing rate over the entire trial. A neuron was classified as a "test cell" if there was a significant (ANOVA; $p<0.01$ ) firing rate increase in one or more perievent histogram bins relative to baseline. Only increases in firing were considered for events in the test phase, which did not all occur at a common location to avoid classifying low, out-of-field firing of a spatially selective cell as a response (e.g., to avoid classifying a place cell with a receptive field in the sample arm and no activity in the test arms as "responsive" to events in the test phase). For perievent histograms in the sample and delay phases in which the location of the rat was fixed at the sample port, the pre-odor interval at the sample port was used as the baseline reference period. A cell was classified as a "sample cell" or "delay cell" if there was a significant change (either enhancement or suppression) in the firing rate of one or more perievent histogram bins relative to pre-odor baseline. Further discriminant analyses were performed then on each event-responsive cell.

Determination of firing selectivity. The test-phase perievent histograms constructed around the test-arm entry and poke response consisted of three factors: position [left/right (L/R)], odor (A/B), and trial type [correct/error $(\mathrm{C} / \mathrm{E})]$. The sample phase and delay phase perievent histograms constructed around odor onset and offset consisted of two factors: odor (A/B) and trial type (correct/error). Note that correct/ error in the sample and delay phases refers to trials in which a nonmatch or match response, respectively, was made in the test phase.

Discriminant analysis (Rencher, 1995) is a mathematical technique to project data in high-dimensional space onto a reduced number of dimensions (i.e., a set of basis vectors) that maximally separate one or more groups. For linear discriminant analysis of perievent activity, this translates to finding weights for each perievent histogram time bin such that the weighted linear sum maximally separates one or more of the groups. This process is equivalent to plotting the perievent firing rate of a cell for each trial in $n$-dimensional space, where $n$ is the number of time bins, and computing directions in $n$-dimensional space along which the groups are maximally separated [see Wiebe and Stäubli (1999) for schematic illustration]. For example, if odor and correct/error are the two factors and the four groups are correct odor A trials, correct odor B trials, error odor A trials, and error odor B trials, and if the perievent firing rate of the cell, $X$, for trial $j$ in time bin $i$ is $x_{\mathrm{ij}}$, then the first direction (first discriminant function) $\mathrm{D}^{1}=\left(\mathrm{d}_{1}^{1}\right.$, $\mathrm{d}_{2}^{1}, \ldots, \mathrm{d}_{\mathrm{n}}^{1}$ ) is computed such that the distribution of

$$
D^{1} \cdot X=\sum_{\mathrm{i}} d_{\mathrm{i}}^{1} \cdot x_{\mathrm{ij}}
$$

across the $j$ trials maximally separates one or more of the groups. The first discriminant function is chosen therefore such that the data projection onto it accounts for the maximal separation between the groups (maximal variance). Mathematically, this is equivalent to finding the eigenvector with the largest eigenvalue $\lambda_{1}$ of the matrix $B \cdot W^{-1}$, where $B$ is the between-group covariance matrix and $W$ is the within-group covariance matrix for the perievent histogram. The second discriminant function $D^{2}=\left(d_{1}^{2}, d_{2}^{2}, \ldots, d_{n}^{2}\right)$ is then selected such that it maximizes the variance between the groups and is uncorrelated (linearly independent) with $\mathrm{D}^{1}$. A total of minimum (number of time bins, number of groups) discriminant functions is calculated in this fashion for each perievent histogram such that successive functions account for maximal variance of the perievent activity of the cell across groups that are linearly independent from previously calculated functions. The proportion of perievent firing variance across trials accounted for by the discriminant function projections $\mathrm{D}^{1} \cdot \mathrm{X}, \mathrm{D}^{2} \cdot \mathrm{X}, \ldots$ is ordered, therefore, from 
highest to lowest. The ability of a discriminant function projection to separate one or more of the groups was determined using the $\chi^{2}$ approximation of the Wilks $\Lambda$ statistic. Significant discriminant function projections $\left(p<0.01 ; \chi^{2}\right)$ were analyzed then using two- and three-way ANOVAs to determine which groups were separated. Cells with discriminant function projections that had a significant main effect (ANOVA; $p<0.01$ ) were deemed selective for that factor (e.g., odor) and to discriminate the two groups in that factor (e.g., odor A versus odor B) in its perievent firing rate.

The degree to which the difference in firing rate between separated groups contributed to the overall perievent firing rate variance across trials was determined by the ratio of the eigenvalue of the corresponding discriminant function to the total firing rate variance in the perievent histogram across trials. Because the discriminant functions are uncorrelated, the eigenvalues additively partition the total firing rate variance across trials, and the percentage of firing rate variance accounted for by the $i$ th discriminant function is given by:

$$
\lambda_{\mathrm{i}} /\left(\sum_{\mathrm{j}} \lambda_{\mathrm{j}}\right) .
$$

The percentage of variance in firing rate across trials accounted for by discriminant functions that separated sample odor A versus B, test odor A versus $\mathrm{B}$, test position left versus right, and correct versus error trials in the test phase was calculated (see Fig. 6A) to compare the relative strength of each correlate. For instance, a discriminant function projection $\mathrm{D} \cdot \mathrm{X}$ which separated odor $\mathrm{A}$ versus odor $\mathrm{B}$ trials and contributed to $80 \%$ of the perievent firing variance of the cell would indicate that $80 \%$ of the variation in perievent activity across trials was attributable to differential activity on odor A versus odor B trials.

\section{Controls for movement}

Because the firing rates of some classes of interneurons are known to be correlated to walking speed (McNaughton et al., 1983a; Rivas et al., 1996), we compared velocity distributions between groups separated by the discriminant analysis, as calculated by subtracting the test-arm entry and nosepoke response times. A significance level of $p>0.05$ (ANOVA) signified that walking speeds on odor A versus odor B, left versus right, or correct versus error trials were indistinguishable. The distance between the entry point of the test arm and the nosepoke port infrared beam was $24 \mathrm{~cm}$, approximately equal to the body length of the rat. In test arms in which a nosepoke was executed, the rats traversed this length rapidly (mean time, $0.920 \mathrm{sec}$ on average for each rat) and in a highly stereotyped fashion (SEM, 0.009). This effectively rules out the possibility that other variants of overt behavior, such as vigorous head movements, etc., could have been responsible for generating the observed position, odor, or correct/error firing selectivity in the test phase. The $0.920 \mathrm{sec}$ average test-arm traversal time was less than the $1 \mathrm{sec}$ length of the perievent firing rate histograms analyzed around the test-arm entry and in the pre-poke period. Hence, the resolution of the walking speed measurement was of the same order of magnitude as the time resolution of the perievent firing rate analyses. In all other perievent histograms analyzed [post-poke in the test phase; odor-fast, odor-slow, and odor-off in the sample phase; and the delay histogram (Table 1 and Fig. 2)], the body and head position of the rat was stationary, with the nose positioned inside 20 -mm-diameter cylindrical nosepoke ports.

\section{RESULTS}

\section{Theta cell activity correlated to DNMS events}

A total of 139 theta cells were isolated from the dentate gyrus $(n=29)$, CA3 $(n=72)$, and CA1 $(n=38)$ fields in 18 rats during criterion performance of the DNMS task. The units were recorded during an average of 24 sessions per animal. A subset of the theta cells was responsive (relative to baseline; ANOVA; $p<$ 0.01 ) to each DNMS event, and many cells responded to more than one event. Some cells exhibited deviations from baseline activity only while the rat moved toward the nosepoke devices in the test phase (Fig. $2 A$ ). Such cells are similar to the theta cells originally described by Ranck (1973), with firing correlated with voluntary motor behavior (Type 1 theta behavior) (Bland et al., 1983). Here, they were classified as test cells (i.e., responsive to events in the test phase). Other cells demonstrated strong responses to the odor delivery in the sample phase, in addition to the locomotion-related activity in the test phase (therefore, both a sample and test cell) (Fig. 2B,C). Such theta cell activity in response to sensory (odor) stimuli during alert immobility, termed Type 2 theta behavior, has been reported previously (Bland et al., 1983; Eichenbaum et al., 1987). Some theta cells demonstrated elevated (Fig. 2D) or suppressed (Fig. $2 E$ ) firing during odor onset and offset in the sample phase and around the nosepoke in the test phase (Fig. 2D). Others maintained elevated firing during the delay interval and were classified as delay cells (Fig. $2 F$ ).

Approximately $97 \%$ of the theta cells in each subfield (135 of 139 overall) were responsive to events in the sample phase (sample cells), 91 of 139 (65\%) in the delay phase (delay cells), and 126 of $139(90 \%)$ in the test phase (test cells) (Table 2). Responsive theta cells were analyzed further to determine whether their activity was selective for odor A/B, correct/error trials, or left/ right position as determined by discriminant analysis $\left(\chi^{2} ; p<\right.$ 0.01 significance criteria) and significant main effects on post hoc ANOVAs $(p<0.01)$.

\section{Sample odor-selective activity restricted to CA1 theta cells and linked to task performance}

Theta cells that discriminated odor A versus B in the sample phase were largely restricted to the CA1 subfield. Examples of two odor-selective CA1 theta cells are shown in Figure 3, $A$ and $B$. Other theta cells exhibited differential activity in response to the sample odor on correct trials in which recognition of the odor occurred later in the test phase, versus error trials in which recognition failed (Fig. $3 C$ ). The head and body position remained constant throughout the sample and delay phases of the task, with the rat's nose positioned inside the cylindrical nosepoke port. Therefore, the odor and correct/error correlates of theta cell responses to the sample stimulus were not the result of or secondary to movement or spatial correlates. Responsive cells in the sample phase (including the odor-fast, odor-slow, and odor-off periods) were tallied then for each subfield (Table 2). Odor selectivity was observed in 26 of 135 (19\%) of the responsive theta cells in the sample phase (compared with 100 of 699 or $14 \%$ for principal cells), one-third (8 of 26) of which fired differentially on correct versus error trials. Ten percent (13 of 135) of the sample theta cells discriminated correct/error trials, the same proportion as was seen in the principal cells (Fig. 4A). Odorselective firing in the sample phase (Fig. $4 B$ ) occurred primarily in CA1 theta cells: 15 of $38(40 \%)$ of the responsive CA1 cells discriminated odor compared with 4 of $27(15 \%)$ in DG and 7 of $70(10 \%)$ in CA3 (CA1 vs DG/CA3; $\chi^{2}$ test, $\chi_{(1)}^{2}=13.90 ; p<$ $0.01)$. This nonhomogeneous pattern of odor selectivity across the hippocampal subfields was similar to that observed for the principal cells (7 of 96 or $7 \%, 67$ of 458 or $14 \%$, and 26 of 145 or $18 \%$ of responsive DG, CA3, and CA1 principal cells, respectively, recorded in the same animals and analyzed in Wiebe and Stäubli, 1999) but was more steeply graded than the principal cell pattern $\left(\chi^{2}\right.$ test, $\left.\chi_{(2)}^{2}=6.12 ; p=0.05\right)$.

\section{Sample-nonspecific delay activity}

Sixty-five percent (91 of 139) of the theta cells in the hippocampus exhibited significantly elevated or suppressed activ- 


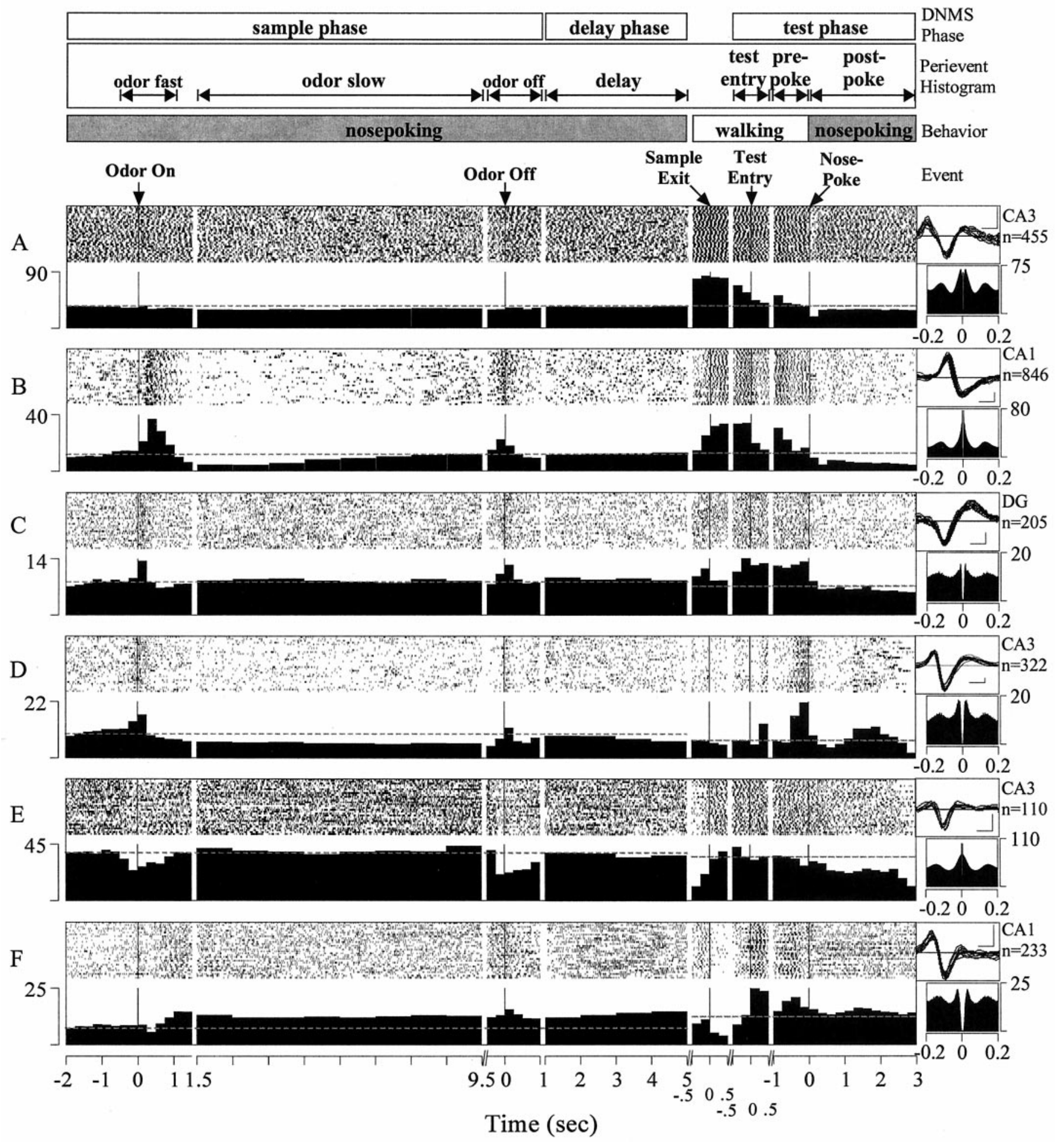

Figure 2. Examples of hippocampal theta cell activity during DNMS task performance. Each panel includes a raster display of 30 representative consecutive trials and a summary histogram of perievent activity in spikes per second summed across all trials in 250 msec bins, except in the slow sample-odor onset and delay intervals in which $1 \mathrm{sec}$ bins were used. The six cells displayed $(A-F)$ were selected as illustrative examples from different recording sessions and were not recorded simultaneously. Event responsiveness was determined by comparing the perievent firing rate with baseline activity. For perievent histograms in the sample and delay phases in which the location of the rat was fixed at the sample nosepoke port, the pre-odor interval was used as the baseline reference period (represented as a dotted line extending throughout the sample and delay phase). A cell was classified as responsive to a sample-phase or delay-phase event if there was a significant change (ANOVA; $p<0.01$ ) in firing in one or more perievent histogram bins. For perievent histograms in the test phase in which the position of the rat changed as it traversed the test arm, the baseline used was mean firing rate over the entire trial (represented as a dotted line extending throughout the test phase). A cell was classified as responsive to an event in the test phase if there was a significant (ANOVA; $p<0.01$ ) increase in activity in one or more of the perievent histogram bins compared with baseline. The extracellularly recorded waveform (negative deflection-down; calibration, $50 \mu \mathrm{V}, 150 \mu \mathrm{sec}$ ), hippocampal field, number of DNMS trials recorded ( $n$ ), and autocorrelogram for each cell are shown to the right of each panel. The autocorrelograms ( $y$-axis, spikes per second; $x$-axis,(Figure legend continues) 
Table 2. Number of responsive theta cells with selective activity in the sample, delay, and test phases

\begin{tabular}{|c|c|c|c|c|c|c|c|c|c|c|c|}
\hline \multirow[b]{2}{*}{$\begin{array}{l}\text { Sample cells } \\
(\% \text { cells recorded })\end{array}$} & DG & CA3 & CA1 & \multirow[b]{2}{*}{ Delay cells } & \multirow{2}{*}{$\begin{array}{l}\text { DG } \\
19 \\
(66 \%)\end{array}$} & \multirow{2}{*}{$\begin{array}{l}\text { CA3 } \\
46 \\
(64 \%)\end{array}$} & \multirow{2}{*}{$\begin{array}{l}\text { CA1 } \\
26 \\
(68 \%)\end{array}$} & \multirow[b]{2}{*}{ Test cells } & \multirow{2}{*}{$\begin{array}{l}\mathrm{DG} \\
25 \\
(86 \%)\end{array}$} & \multirow{2}{*}{$\begin{array}{l}\text { CA3 } \\
65 \\
(90 \%)\end{array}$} & \multirow{2}{*}{$\begin{array}{l}\text { CA1 } \\
36 \\
(95 \%)\end{array}$} \\
\hline & $\begin{array}{l}27 \\
(93 \%)\end{array}$ & $\begin{array}{l}70 \\
(97 \%)\end{array}$ & $\begin{array}{l}38 \\
(100 \%)\end{array}$ & & & & & & & & \\
\hline Odor (selective) & 3 & 4 & 11 & Odor & 0 & 0 & 0 & Odor & 0 & 1 & 0 \\
\hline $\mathrm{C} / \mathrm{E}$ & 0 & 3 & 2 & $\mathrm{C} / \mathrm{E}$ & 0 & 0 & 0 & $\mathrm{C} / \mathrm{E}$ & 0 & 1 & 1 \\
\hline \multirow[t]{8}{*}{ Odor and $\mathrm{C} / \mathrm{E}$} & 1 & 3 & 4 & Odor and $\mathrm{C} / \mathrm{E}$ & 0 & 0 & 0 & Position & 14 & 23 & 11 \\
\hline & & & & & & & & Odor and position & 4 & 11 & 7 \\
\hline & & & & & & & & $\mathrm{C} / \mathrm{E}$ and position & 2 & 11 & 13 \\
\hline & & & & & & & & Odor and $\mathrm{C} / \mathrm{E}$ & 0 & 1 & 0 \\
\hline & & & & & & & & Odor and $\mathrm{C} / \mathrm{E}$ and position & 3 & 14 & 2 \\
\hline & & & & & & & & Exclusive* odor & 0 & 0 & 0 \\
\hline & & & & & & & & Exclusive* $\mathrm{C} / \mathrm{E}$ & 0 & 0 & 1 \\
\hline & & & & & & & & Exclusive* $^{*}$ position & 12 & 16 & 9 \\
\hline
\end{tabular}

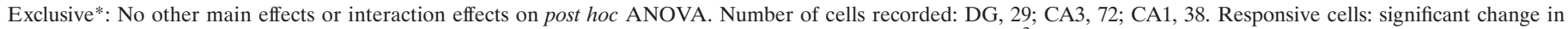

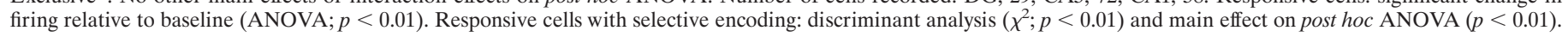

ity at the sample port location in the delay relative to the pre-odor period but, like the principal cells, none (0 of 91) differentiated odor $\mathrm{A}$ versus odor $\mathrm{B}$ or correct versus error (C/E) trials (Table 2, Fig. 4A).

\section{Recognition phase activity}

Central to the DNMS task is the ability to discriminate the test odors and then make a match/nonmatch comparison with the sample odor held in memory. Individual theta cells were found to discriminate various combinations of correct nonmatch/ error match $(\mathrm{C} / \mathrm{E})$, odor $\mathrm{A} / \mathrm{B}$, and left/right position in the test phase. Some exhibited activity that discriminated only left/ right position (Fig. 3D) or correct/error trials (Fig. 3E), whereas others demonstrated conjunctive position, odor, and $\mathrm{C} / \mathrm{E}$ correlates (Fig. 3F).

Theta cell odor $A / B$, correct/error, and left/right position selectivity in the test phase not attributable to differential walking speeds between groups

The test phase differed from the sample and delay phases in that the rat was walking while smelling and discriminating the odor stimuli. The majority of the test cells with selective odor, correct/ error, or position firing while the rat was moving from the testarm entrance to the poke port (i.e., in the test-entry and pre-poke periods) did not have significant differences (ANOVA; $p>0.05$ ) in walking speed for odor A versus odor B trials (20 of 23 cells;
$87 \%$ ), correct versus error trials (20 of $25 ; 80 \%$ ), and left versus right position (79 of $104 ; 76 \%$ ), respectively. The walking speed was calculated using the time between test-arm entry and the end-of-arm nosepoke $[0.920 \pm 0.009 \mathrm{sec}$ (mean \pm SEM) on average for each rat]. This indicates that the selectivity of the theta cell firing observed before the nosepoke in the test phase cannot be attributed to differential rates of locomotion within the different analysis groups.

\section{Correct/error-selective cells with reinforcement-correlated activity after the test nosepoke excluded from subsequent analyses}

To determine whether correct/error-selective firing immediately after the test nosepoke was associated with the behavioral execution of the nosepoke or was attributable to differential responding to the water reward and light flash, the reinforcement signal was delayed $1.5 \mathrm{sec}$ on a select number of randomly interspersed trials. Correct/error-selective cells in the postpoke period were classified as either reinforcement-correlated or poke-correlated on the basis of whether their poke-aligned or reinforcement-aligned perievent histogram contained the larger peak firing rate. An example of a reinforcementcorrelated correct/error cell is shown in Figure $5 A$. The elevated activity of the cell after error match, but not correct nonmatch, responses was better correlated with the flash reinforcement than the nosepoke response (i.e., more temporally

\section{$\longleftarrow$}

seconds) show a rhythmicity in the theta range for each cell [peak in $80-200 \mathrm{msec}$ range $(5-12 \mathrm{~Hz})$ in autocorrelogram]. The DNMS phase, perievent histogram limits, and behavior of the rat around each DNMS event are shown at the top of the figure. $A$, A theta cell that exhibited movement (locomotion)-correlated activity similar to that described by Ranck (1973). The cell had elevated firing while exiting the sample arm $\left(F_{(1,97998)}=2249.20\right.$; $p<0.01)$, entering the test arms $\left(F_{(1,97998)}=650.70 ; p<0.01\right)$, and in the pre-poke period $\left(F_{(1,97998)}=148.30 ; p<0.01\right)$. B, A cell with increased activity around sample odor onset (odor fast; $F_{(1,8623)}=2536.50 ; p<0.01$ ) and offset (odor off; $F_{(1,8623)}=476.5 ; p<0.01$ ), suppression during the slow sample odor onset period (odor slow; $F_{(1,2782)}=636.85 ; p<0.01$ ), and elevated firing on exit of the sample arm $\left(F_{(1,167376)}=1959.00 ; p<0.01\right)$, entry into the test $\operatorname{arms}\left(F_{(1.167376)}=1493.40 ; p<0.01\right)$, and in the preresponse period $\left(F_{(1.167376)}=968.20 ; p<0.01\right)$. $C$, A cell with increased activity during sample odor onset (odor fast; $F_{(1,2035)}=83.06 ; p<0.01$ ) and offset (odor off; $F_{(1,2035)}=52.27 ; p<0.01$ ), sample arm exit $\left(F_{(1,53409)}=45.92 ; p<0.01\right)$, test-arm entry $\left(F_{(1,53409)}=155.11 ; p<0.01\right)$, and the preresponse period $\left(F_{(1,53409)}=77.29 ; p<0.01\right)$. $D$, A cell with increased firing in response to sample odor onset (odor fast; $\left.F_{(1,3246)}=202.61 ; p<0.01\right)$ and offset (odor off; $\left.F_{(1,3246)}=82.23 ; p<0.01\right)$, decreased firing in the slow odor on $\left(\right.$ odor slow; $F_{(1,1062)}=$ $144.76 ; p<0.01)$ and delay $\left(F_{(1,1062)}=19.85 ; p<0.01\right)$ periods, and increased activity on entry into the test arms $\left(F_{(1.51872)}=311.18 ; p<0.01\right)$, and in the preresponse $\left(F_{(1,51872)}=941.21 ; p<0.01\right)$ and postresponse $\left(F_{(1,51872)}=101.83 ; p<0.01\right)$ periods. $E$, A cell that exhibited suppressed firing during the fast sample odor on $\left(F_{(1,1462)}=36.14 ; p<0.01\right)$ and off $\left(F_{(1,1462)}=53.87 ; p<0.01\right)$ periods, increased activity in the slow odor on period $\left(F_{(1.436)}=\right.$ $7.12 ; p<0.01)$, and elevated firing on exiting the sample arm $\left(F_{(1,25639)}=107.08 ; p<0.01\right)$ and entering the test arms $\left(F_{(1,25639)}=25.49 ; p<0.01\right)$. $F$, A cell that exhibited elevated activity in the fast (odor fast; $\left.F_{(1,2344)}=239.06 ; p<0.01\right)$ and slow (odor slow; $\left.F_{(1,757)}=230.51 ; p<0.01\right)$ sample on periods, on sample odor termination (odor off; $\left.F_{(1,2344)}=288.55 ; p<0.01\right)$, and in the delay period $\left(F_{(1,757)}=103.22 ; p<0.01\right)$, on entry into the test arms $\left(F_{(1,47923)}=696.67 ; p<0.01\right)$, and in the preresponse $\left(F_{(1,47923)}=346.54 ; p<0.01\right)$ and postresponse $\left(F_{(1,47923)}=122.45 ; p<0.01\right)$ periods. 


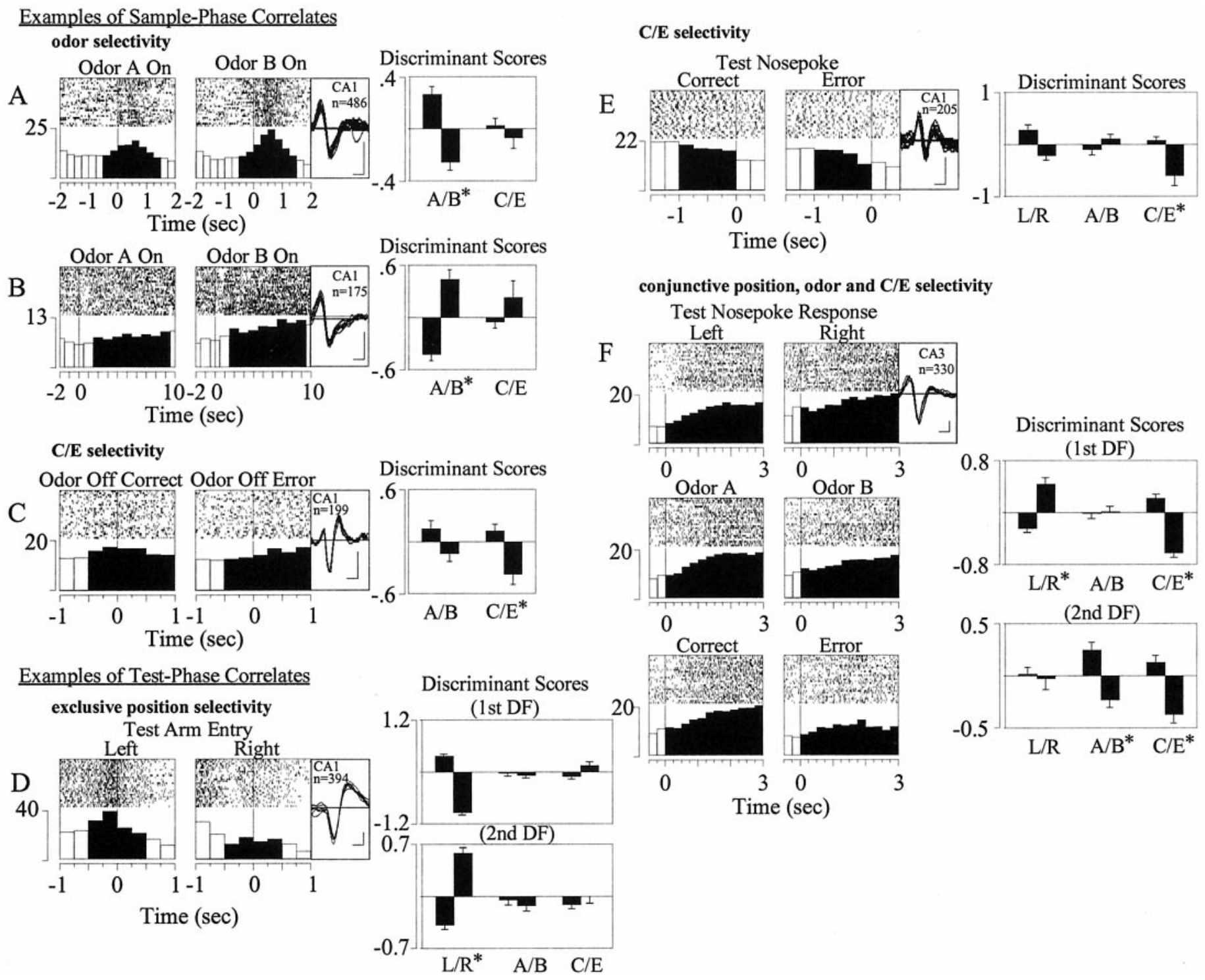

Figure 3. Examples of odor, position, and correct/error-selective firing in theta cells. Panels show a raster display of 25 representative consecutive trials and a summary histogram of all trials recorded for each cell. Waveform (negative deflection-down; calibration, $50 \mu \mathrm{V}, 150 \mu \mathrm{sec}$ ), hippocampal field, number of trials recorded $(n)$, and significant $\left(\chi^{2} ; p<0.01\right)$ discriminant function $(D F)$ projection scores $($ mean + SEM) for odor A/B $(A / B)$, correct/error $(C / E)$, or left/right $(L / R)$ arm position are shown to the right of each panel. * indicates significant $(p<0.01)$ main effect of discriminant projection scores in the post hoc two-way or three-way ANOVAs. Sample Phase, A, B, Cells selective for odor but not correct/error trials in their fast $\left[A, \chi_{(24)}^{2}=59.11 ; p<0.01\right.$; odor, $F_{(1,482)}=24.78 ; p<0.01 ; \mathrm{C} / \mathrm{E}, F_{(1,482)}=0.19$, not significant $\left.(\mathrm{NS})\right]$ and slow $\left(B, \chi_{(24)}^{2}=65.27 ; p<0.01 ;\right.$ odor, $F_{(1,171)}=$ $\left.29.21 ; p<0.01 ; \mathrm{C} / \mathrm{E}, F_{(1.171)}=3.44, \mathrm{NS}\right)$ sample odor responses. $C$, A cell selective for correct/error trials but not odor on termination of the sample odor $\left(\chi_{(18)}^{2}=38.91 ; p<0.01\right.$; odor, $F_{(1,195)}=0.65$, NS; C/E, $\left.F_{(1,195)}=9.16 ; p<0.01\right)$. Test Phase, $D$, Cell with exclusive position $(L / R)$ selectivity around test-arm entry. The cell had two significant discriminant functions, both of which discriminated only position: $\mathrm{DF}_{1}($ top $), \chi^{2}(28)=536.82 ; p<0.01$; position, $F_{(1,386)}=66.09 ; p<0.01$; odor, $F_{(1,386)}=1.41$, NS; C/E, $F_{(1,386)}=0.82$, NS; and $\mathrm{DF}_{2}($ bottom $), \chi_{(18)}^{2}=246.48 ; p<0.01 ;$ position, $F_{(1,386)}=$ 26.88; $p<0.01$; odor, $F_{(1,386)}=0.81, \mathrm{NS} ; \mathrm{C} / \mathrm{E}, F_{(1,386)}=2.50$, NS. The rat's walking speed in the left and right arms was indistinguishable $($ ANOVA; $p>0.05) . E$, Cell with selective correct/error activity in the preresponse period $\left(\chi_{(24)}^{2}=59.53 ; p<0.01 ;\right.$ position, $F_{(1.197)}=2.36, \mathrm{NS}$; odor, $F_{(1.197)}=$ 6.28 , NS; C/E, $F_{(1,197)}=19.41 ; p<0.01$ ). The rat's walking speed for correct versus error trials was indistinguishable (ANOVA; $p>0.05$ ). $F$, Cell with position, odor, and correct/error correlates in the post-poke period. The first significant discriminant function (top) distinguished position and correct/error $\left(\chi_{(84)}^{2}=202.42 ; p<0.01\right.$; position, $F_{(1,322)}=7.95 ; p<0.01$; odor, $F_{(1,322)}=0.22$, NS; C/E, $\left.F_{(1,322)}=11.88 ; p<0.01\right)$. The second significant discriminant function (bottom) separated odor A/B and correct/error trials $\left(\chi_{(66)}^{2}=104.25 ; p<0.01 ;\right.$ position, $F_{(1,322)}=1.03, \mathrm{NS}$; odor, $F_{(1,322)}=14.46$; $\left.p<0.01 ; \mathrm{C} / \mathrm{E}, F_{(1,322)}=18.71 ; p<0.01\right)$.

locked in the flash-centered versus the poke-centered histogram), indicating that the activity could be interpreted as a response to the light flash. An example of a poke-correlated cell is shown in Figure $5 B$. The increased activity after correct nonmatch responses compared with error match responses was correlated better with the time of the poke than the water reinforcement delivery (i.e., more temporally locked in the poke-centered versus the reinforcement-centered histogram), indicating that the activity of the cell represented the execution of a correct nosepoke and not simply a response to the water delivery. Reinforcement-correlated $\mathrm{C} / \mathrm{E}$ cells were discarded, and only $\mathrm{C} / \mathrm{E}$-selective cells with poke-correlated activity were included from the post-poke period in subsequent analyses (Table 2, Figs. 4, 6). 


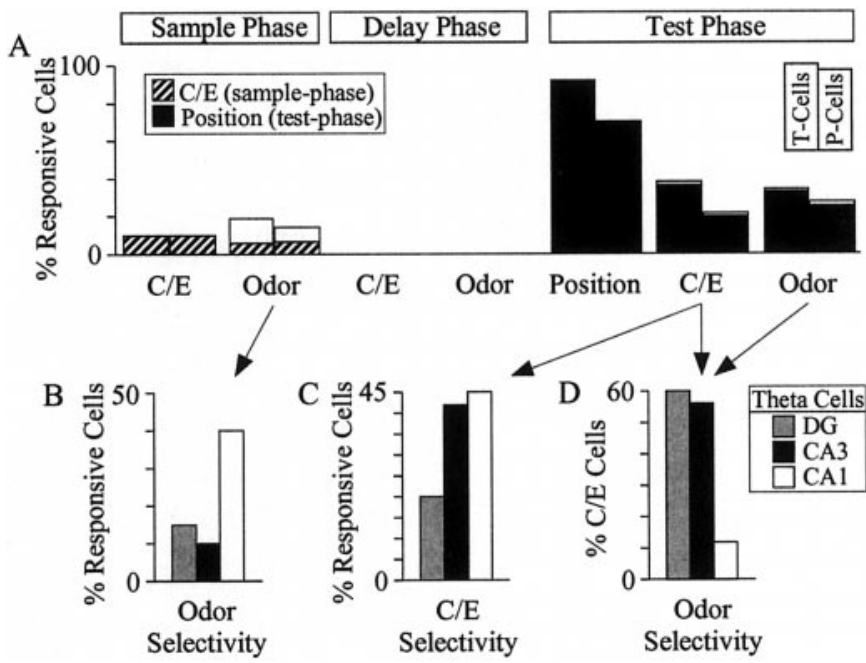

Figure 4. Summary of position, odor, and correct/error recognition correlates of hippocampal theta cells in the DNMS task. $A$, Correlates of event-responsive theta interneurons (T-Cells, left bars) compared with that of principal cells ( $P$-Cells, right bars; taken from Wiebe and Stäubli, 1999). Ten percent of the responsive theta cells in the sample phase fired differentially on correct versus error trials. Sample odor selectivity was observed in $20 \%$ of the theta cells (compared with $14 \%$ for the principal cells), roughly one-third of which fired differentially on correct versus

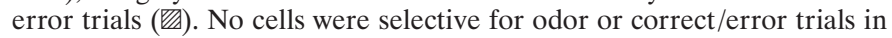
the delay period. In the test phase, a greater proportion of responsive theta cells were selective for position, correct/error, and odor than were the responsive principal cells (position, theta cells, 91\%; principal cells, $70 \%$; C/E, theta cells, 38\%; principal cells, $21 \%$; odor, theta cells, $34 \%$; principal cells, 27\%). Spatial selectivity was more than twice as predominant as odor and $\mathrm{C} / \mathrm{E}$ selectivity for responsive theta cells, and almost all odor and $\mathrm{C} / \mathrm{E}$ cells had conjunctive spatial correlates $(\mathbf{\square})$. $B$, Sample odor selectivity in hippocampal theta cells was restricted primarily to the CA1 subfield, with odor selectivity in $40 \%$ of responsive cells in CA1, compared with 10 and $15 \%$ in CA3 and DG, respectively (CA1 vs DG/CA3; $\chi^{2}$ test, $\left.\chi_{(1)}^{2}=13.90 ; p<0.01\right)$. $C$, Correct nonmatch/error matchselective theta cells in the test phase were more than twice as predominant in the CA3/1 regions $(\sim 43 \%)$ than the dentate gyrus $(20 \%)\left(\chi^{2}\right.$ test, $\left.\chi_{(1)}^{2}=4.33 ; p<0.05\right)$. D , Odor selectivity of the correct/error cells in the dentate and CA3 fields was near $60 \%$, but only $12 \%$ in CA1. The distribution of odor selectivity in the test-phase $\mathrm{C} / \mathrm{E}$ cells was inverse and statistically distinct $\left(\chi_{(2)}^{2}=58.2 ; p<0.01\right)$ from that of the responsive theta cells in the sample phase in $B$.

Correct/error recognition signaling most prominent in $C A 3 / 1$ subfields, odor-selective in $D G / C A 3$, and integrated with spatial representations

Responsive theta cells with odor, correct/error (including $15 \mathrm{C} / \mathrm{E}$ cells in the test-entry period, $15 \mathrm{C} / \mathrm{E}$ cells in the pre-poke period, and 28 poke-correlated $\mathrm{C} / \mathrm{E}$ cells from the post-poke period), and position selectivity were tallied over all three test-phase perievent histograms, as shown in Table 2 and Figure $4 A$. Position (115 of $126 ; 91 \%$ ), odor (43 of $126 ; 34 \%$ ), and correct/error selectivity (48 of $126 ; 38 \%$ ) in the test phase occurred in a greater proportion of responsive theta cells than principal cells [400 of 571 (70\%), 155 of 571 (27\%), and 121 of 571 (21\%), respectively). Roughly one-third (37 of 115) of the spatial theta cells were selective for position exclusively with no significant (ANOVA; $p<0.01$ ) main or interaction effects with regard to odor or $\mathrm{C} / \mathrm{E}$, whereas $\sim 95 \%$ of the $\mathrm{C} / \mathrm{E}$ (45 of 48 ) and odor (41 of 43) cells had spatial correlates (Table 2, Fig. 4A).

Correct/error trial-selective activity was seen in twice as many theta cells in CA3/1 (43 of 101 or $43 \%$ of responsive neurons) as in DG $(5$ of $25 ; 20 \%)\left(\chi^{2}\right.$ test; $\left.\chi^{2}{ }_{(1)}=4.33 ; p<0.05\right)$ (Fig. $\left.4 C\right)$.
The majority of correct/error cells in DG and CA3 were odor selective (18 of $32 ; 56 \%$ ), whereas only 2 of $16(12 \%) \mathrm{C} / \mathrm{E}$ cells in CA1 had conjunctive odor correlates (Fig. 4D). This distribution of odor selectivity of $\mathrm{C} / \mathrm{E}$ cells in the test phase was more steeply graded $\left(\chi^{2}\right.$ test; $\left.\chi^{2}{ }_{(2)}=12.78 ; p<0.01\right)$ than that observed for the C/E-selective principal cells [10 of 17 (59\%) in DG, 32 of 76 $(42 \%)$ in CA3, and 10 of $28(36 \%)$ in CA1] and was inverse and distinct $\left(\chi^{2}\right.$ test; $\left.\chi_{(2)}^{2}=58.2 ; p<0.01\right)$ from the theta cell odor-selectivity distribution in sample phase in Figure $4 B$. The distribution of odor selectivity of responsive theta cells in the test phase [7 of 25 (28\%) in DG, 27 of 65 (42\%) in CA3, and 9 of 36 $(25 \%)$ in CA1], although not inversely distributed across subfields relative to the sample phase, was statistically different $\left(\chi^{2}\right.$ test; $\left.\chi_{(2)}^{2}=21.6 ; p<0.01\right)$ from the sample-phase distribution.

Equivalent relative strength of odor, position, and correct/error recognition correlates in interneurons and principal cells

For each odor-selective cell in the sample phase or position-, $\mathrm{C} / \mathrm{E}$-, or odor-selective cell in the test phase, we calculated the percentage of the total variance in perievent firing across trials accounted for by the associated discriminant functions. A summary of the pooled results over all DNMS events for both interneurons and principal cells is shown in Figure $6 A$. The percentage of total perievent firing rate variance accounted for by differential sample odor A versus B, test odor A versus B, test left versus right position, and test correct versus error trial activity for interneurons did not differ from that of the principal cells for each of the four variables (ANOVA; $p>0.1$; pairwise comparisons). Nor was there any significant difference in percentage of total perievent firing variance among the four variables for the interneurons (ANOVA; $p>0.1$ ).

Majority of $C / E$ theta cells exhibited greater activity on correct trials than error trials, but with smaller difference in firing rate compared with principal cells

To compare the magnitude of interneuron correct/error recognition correlates in absolute terms with that of principal cells, we calculated the ratio of the mean perievent activity (averaging across all time bins in each perievent histogram) for correct $(\mathrm{C})$ and error $(\mathrm{E})$ trials, $[(\mathrm{C}-\mathrm{E}) /(\mathrm{C}+\mathrm{E})]$, for all $\mathrm{C} / \mathrm{E}$-selective cells. The majority of both $\mathrm{C} / \mathrm{E}$-selective principal cells (84 of 121; $70 \%$ ) and interneurons (38 of 48; 79\%) exhibited higher firing rates on correct nonmatch trials than error match trials. The ratio of correct to error activity, however, was considerably smaller in interneurons [ 45 of $48(94 \%)$ of the theta cells with $<20 \%$ difference] compared with the principal cell population [55 of 124 (44\%) of the cells with $>20 \%$ difference] (Fig. $6 B$ ). The inset portion of Figure $6 \mathrm{~B}$ illustrates that the majority of $\mathrm{C} / \mathrm{E}$ theta cells did exhibit moderately $(>0 \%,<25 \%)$ higher firing rates on correct nonmatch trials than error match trials.

\section{DISCUSSION}

Since 1973 when Ranck first described the correlation between theta cell activity and the movement/arousal-related hippocampal EEG theta rhythm (Ranck, 1973), most theta cell recording studies have involved tasks with modest cognitive demands, such as searching for randomly distributed food pellets, traversing linear tracks or mazes, simple sensory discrimination, or eyeblink conditioning. In addition to the behavioral (motor) correlates (O'Keefe, 1976), some place (McNaughton et al., 1983a; Kubie et al., 1990) and $\mathrm{S}^{+} / \mathrm{S}^{-}$specificity (Christian and Deadwyler, 1986; Foster et al., 1987) has been observed as well as activity associ- 
Figure 5. Determination of poke-correlated versus reinforcement-correlated correct/ error-selective firing in the post-poke period. Panels show a perievent histogram of all trials recorded for each cell and a raster display of 15 representative consecutive trials. Waveform (negative deflection-down; calibration, $50 \mu \mathrm{V}, 150 \mu \mathrm{sec})$, hippocampal field, and number of trials recorded $(n)$ are shown to the right. A, Top panels, Cell with elevated activity after error (right) relative to correct (left) poke responses $\left(\chi^{2}{ }_{(84)}=337.94 ; p<0.01 ; \mathrm{C} / \mathrm{E}\right.$, $\left.F_{(1,230)}=197.41 ; p<0.01\right)$. The histograms contain both trials in which the reinforcement signal was immediate and trials in which it was delayed $1.5 \mathrm{sec}$. Bottom panels, Perievent histogram of activity around the error poke response (left) and the flash reinforcement signal (right). The activity was better time-locked (i.e., larger maximal firing rate, signified by open arrowheads) to the flash reinforcement than to the poke response and therefore was classified as reinforcement correlated. $B$, Top panels, Cell with more robust activity after correct poke responses $(l e f t)$ than after error poke responses (right) (second DF, $\chi_{(66)}^{2}=227.75 ; p<0.01 ; \mathrm{C} / \mathrm{E}, F_{(1,428)}=58.33 ; p<0.01$ ). Bottom panels, Perievent histogram of activity around the correct poke response (left) and the water reinforcement (right). The activity was better time-locked (i.e., larger maximal firing rate) to the poke response than to the water reinforcement and therefore was classified as poke-correlated. Cells with reinforcement-correlated correct/error selectivity were discarded. Only cells with correct/error-selective activity associated with the nosepoke (poke-correlated) were included in the summary tallies (Table 2, Figs. 4, 6).

ated with learned conditioned responses (McEchron and Disterhoft, 1997). In the present study, we analyzed theta cell responses to stimuli representing cues in a cognitively demanding, hippocampally dependent (Wood et al., 1993; Alvarez et al., 1995; Hampson et al., 1999) recognition memory task. The main findings were: (1) theta cell responses to events in an olfactory DNMS task represent odor, position, and match/nonmatch recognition comparisons with the same percentage of perievent firing variance across trials as hippocampal principal cells; (2) conjunctive spatial with odor and correct/error recognition correlates; (3) inverted sample-phase versus recognition-phase distributions of theta cell odor specificity across the hippocampal subfields, similar to that of the principal cells but with greater contrast between the CA1 and DG/CA3 fields; and (4) greater discriminative match/nonmatch activity on correct versus error trials. A discussion of each finding and its relevance to hippocampal processing during recognition memory follows.

\section{Theta cell and principal cell cognitive firing correlates equivalent in magnitude}

The olfactory, spatial, and correct/error recognition correlates of theta cells represented equivalent proportions of variance in perievent firing rate across trials and were indistinguishable from that of principal cells. Previous investigations of theta cells, like the present study, have reported activity correlated with active stimulus (odor) cue sampling (type 2 theta behavior; alert immobility with presentation of sensory stimuli) and locomotion (type 1 theta behavior; voluntary motor patterns) (Ranck, 1973; Bland et al., 1983; Eichenbaum et al., 1987). Their failure to report perceptual and cognitive firing correlates may be attributable to the relative insensitivity of univariate statistics (ANOVAs) typically used to analyze perievent activity, compared with multivariate discriminant analysis that incorporates the temporal structure of the firing patterns. In the past, however, most studies of hippocampal recognition memory have focused on complex-spike principal cells and not theta interneurons (Otto and Eichenbaum, 1992; Sakurai, 1994; Deadwyler et al., 1996; Wood et al., 1999).

The odor, correct/error, and position selectivity could not be attributed to movement-related activity. In the sample and delay phases, the head and body position of the rat was constant. In the test phase, the majority of theta cells with odor, $\mathrm{C} / \mathrm{E}$, or position correlates had statistically indistinguishable walking speeds across the group categories. The strength of theta cell firing could have correlated with the magnitude of hippocampal EEG theta, however. EEG theta was likely robust during odor sampling in the sample phase (type 2 theta) and during odor sampling and locomotion (type 1 theta) in the test phase (Bland et al., 1983; Eichenbaum et al., 1987), but diminished in the delay when no odors were present and the rat's position remained fixed. This may explain the reduced number of responsive cells in the delay $(\sim 65 \%)$ relative to the sample and test $(>90 \%)$ phases (Table 2$)$. It is possible that the correct/error-selective theta cell activity was paralleled by corresponding changes in hippocampal EEG theta; correlations between EEG theta and hippocampal-dependent memory performance have been observed previously (Winson, 1978; Givens and Olton, 1994; Stäubli and Xu, 1995; Burgess and Gruzelier, 1997). It is unlikely, however, that the EEG theta differed significantly with left/right position or odor identity. No studies to date have reported stimulus cue selectivity, either spatial or nonspatial, in the hippocampal EEG theta. Moreover, the EEG theta would have to have been nonuniformly present in the different hippocampal subfields to underlie the regional differences in theta cell firing correlates. Nevertheless, additional experiments are required to determine the exact relationship between the cognitive interneuron firing correlates and the EEG theta in each hippocampal subfield.

\section{Integration of odor and recognition memory correlates with spatial representations}

Odor and correct/error recognition correlates were present both in the sample phase, in which the spatial position was fixed, and the test phase in which position varied (left/right arm). In the test phase, the majority of odor and correct/error-selective cells had conjunctive spatial correlates, whereas a substantial number of responsive cells $(38 \%)$ had pure position correlates. This indicates that when position was allowed to vary in the test phase, 
A

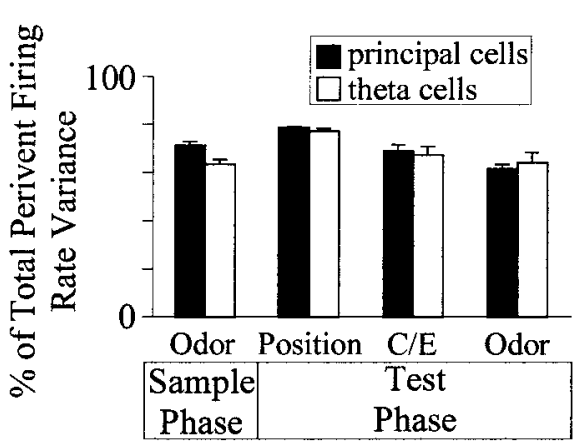

B

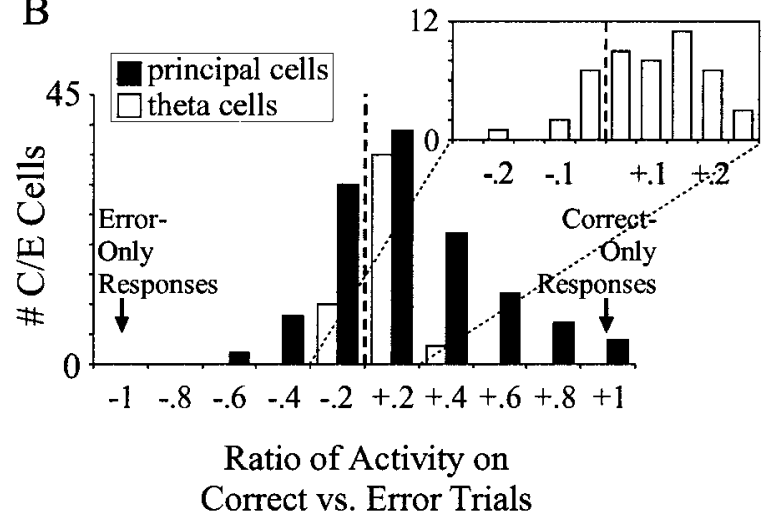

Figure 6. Comparison of the magnitude of theta cell and principal cell firing correlates. $A$, Percentage of the total perievent firing rate variance accounted for by discriminant function projections that distinguished odor $(\mathrm{A} / \mathrm{B})$ in the sample phase and position $(\mathrm{L} / \mathrm{R})$, odor $(\mathrm{A} / \mathrm{B})$, and correct/error $(C / E)$ trials in the test phase in hippocampal theta cells and principal cells. There was no significant difference in the proportion of the total perievent firing rate variance contained in the theta cell correlates versus principal cell correlates for the sample odor [ANOVA; $F_{(1,141)}=$ 0.080 ; not significant (NS)] or test left/right position $\left(F_{(1,947)}=0.002 ; \mathrm{NS}\right)$, odor $\left(F_{(1,238)}=0.003 ; \mathrm{NS}\right)$, or correct/error $\left(F_{(1,193)} \stackrel{\text { a }}{=} 0.002 ; \mathrm{NS}\right)$. The magnitude of the theta cell perievent firing variance accounted for by the sample odor and test position, odor, and correct/error correlates did not differ significantly across the four groups $\left(F_{(3,382)}=0.011 ; \mathrm{NS}\right)$. B, Ratio of the mean perievent activity (averaging across all time bins in each perievent histogram) of correct/error-selective cells on correct $(C)$ versus error $(E)$ trials $[(C-E) /(C+E)]$. Although, like principal cells, the majority $(79 \%)$ of the $\mathrm{C} / \mathrm{E}$ theta cells in the test phase exhibited greater activity in correct nonmatch trials than in error match trials (i.e., ratio $>0$ ), the ratio of activity was smaller (most $\leq 20 \%$ ) than for principal cells (many with $\geq 40 \%$ ). Inset: Interneuron distribution around the $x$-axis origin. Most interneurons had moderately greater activity on correct trials than error trials. (Note: +0.2 implies $0-20 \%$ increase in activity on correct versus error trials, +0.4 implies $20-40 \%$ increase, etc., -0.2 implies 0-20\% decrease, etc.)

perceptual odor and cognitive memory representations became incorporated into the spatial map of the interneurons. The spatially dependent odor and correct/error memory correlates were not smaller in magnitude or secondary to the spatial correlates, however. The proportion of perievent firing variance accounted for by the odor and correct/error memory correlates in the test phase was equivalent to that of both the spatial correlates in the test phase and the odor correlates in the sample phase, in which position was constant (Fig. 6A). The large percentage of responsive theta cells in the test phase with $\mathrm{L} / \mathrm{R}$ place specificity $(91 \%$, compared with $70 \%$ of principal cells, shown in Fig. $4 A$ ) may be attributable to their relatively large place fields (McNaughton et al., 1983a; Kubie et al., 1990).

\section{Sample cue-selective activity restricted to CA1 and linked to task performance}

An advantage of the simultaneous DNMS experimental design used in this study was that the sample and test phases were spatially and temporally distinct, allowing comparisons to be made between theta cell responses to stimuli presented in the acquisition versus recall phase of the task. In the sample phase, odor-selective theta cell activity was largely restricted to the CA1 field (Figs. $4 B, 7 A$ ), perhaps because of the direct entorhinal cortex $\rightarrow$ CA1 perforant path projection (Amaral and Witter, 1989). The fact that activity in one-third of the odor-selective theta cells also predicted performance in the test phase (differential activity in the sample phase on correct versus error trials) suggests that this sample odor representation may be important for mediating its memory across the delay. The correct/error correlate in the sample phase (as well as the test phase) could represent a miscoding of the odor cue (Hampson and Deadwyler, 1996) or a more general cognitive (e.g., attention) signal required for accurate recall in the task.

\section{Behaviorally relevant recognition memory signal concentrated in CA fields, but transitions from cue- specific to cue-general at the CA3-CA1 boundary}

Differential unit responses to test stimuli that match versus nonmatch the sample have been reported in the hippocampus of both monkeys (Rolls et al., 1993) and rats (Otto and Eichenbaum, 1992; Wiebe and Stäubli, 1999; Wood et al., 1999). The match/ nonmatch signals have been interpreted as the neuronal substrate for recognition memory, contributing to the animal's decision about whether stimuli have been encountered in the recent past. Most of these studies however, because of the use of the continuous DNMS paradigm with short delays, had few error trials and subsequently were unable to evaluate the behavioral relevance of these recognition signals. The more robust theta cell activity on nonmatch versus match trials that was observed here (Fig. 6B) provides evidence for the presence of a match/nonmatch comparison signal on correct trials in which recognition occurred and its absence on error trials in which recognition failed. The fact that the correct/error correlates were present during and immediately after odor selection in the test phase but before delivery of the confirmatory water or light-flash reinforcement suggests that these signals represent recognition memory codes involved in the decision-making process at the behavioral level. The match/ nonmatch theta cells were located primarily in the CA3 and CA1 subfields (Fig. 4C). The odor specificity of the match/nonmatch signals, however, was much lower in CA1 than in DG and CA3 (Figs. $4 D, 7 B$ ). Together, this suggests that theta interneuron processing may facilitate the transformation of cue-specific cortical memory signals (Young et al., 1997) into cue-general CA1 recognition memory representations (Eichenbaum et al., 1996; Wiebe and Stäubli, 1999) as they pass through the $\mathrm{DG} \rightarrow \mathrm{CA} 3 \rightarrow \mathrm{CA} 1$ principal cell trisynaptic circuit during recall.

\section{Source of cognitive theta cell firing correlates}

Hippocampal interneurons are driven by feedforward excitatory inputs from extrahippocampal (entorhinal cortex) and intrahippocampal sources (Buzsaki, 1984; Freund and Buzsaki, 1996), as well as by recurrent feedback projections from local principal cells (Andersen et al., 1964). It is possible that the theta cell firing correlates are derived largely from the neighboring principal cells and serve primarily to regulate principal cell activity via feedback 
Figure 7. Schematic diagram of hippocampal theta cell firing correlates during memory acquisition and recall. $A$, Odor cue-specific activity ( filled circles) in the sample phase is restricted to the CA1 field, perhaps transferred from the parahippocampal cortex $(P H C)$ via the direct perforant path projection. $B$, Test-phase correct nonmatch/error match $(C / E)$ comparisons with the sample held in memory occur predominantly in CA3 and CA1 and not in the dentate gyrus $(D G)$. The match/nonmatch comparison signal is stronger on correct trials, in which accurate memory of the sample is demonstrated, and weaker on error trials, in which memory for the sample fails. The correct/error recognition signaling is odor-specific in DG and CA3 and odor-general in CA1. During recall, therefore, theta cell activity con-

tributes to the transformation of cue-dependent cortical memory signals into abstracted, cue-general memory signals as the match/nonmatch recognition signals pass through the $\mathrm{DG} \rightarrow \mathrm{CA} 3 \rightarrow \mathrm{CA} 1$ circuit.

inhibition. The existence of the feedforward pathways, however, leaves open the possibility that the theta cell correlates are not merely the consequence of local principal cell activity but rather play a direct role in producing the principal cell memory correlates. Both the feedforward and feedback systems may be involved in generating the inverted distribution of stimulus-specific responses of principal cells across the hippocampal subfields during memory acquisition (maximal in CA1, minimal in DG) versus recall (maximal in DG, minimal in CA1) (Wiebe and Stäubli, 1999). Although the extent to which the theta cell correlates are driven by local recurrent granule and pyramidal cell projections remains uncertain, the present findings suggest that theta cells actively participate in hippocampal recognition memory processing.

\section{REFERENCES}

Alvarez P, Zola-Morgan S, Squire LR (1995) Damage limited to the hippocampal region produces long-lasting impairment in monkeys. J Neurosci 15:3796-3807.

Amaral DG, Witter MP (1989) The three-dimensional organization of the hippocampal formation: a review of anatomical data. Neuroscience 31:571-591.

Andersen P, Eccles JC, Loyning Y (1963) Recurrent inhibition in the hippocampus with identification of the inhibitory cell and its synapse. Nature 198:540-542.

Andersen P, Eccles JC, Loyning Y (1964) Location of synaptic inhibitory synapses on hippocampal pyramids. J Neurophysiol 27:592-607.

Bland BH, Seto MG, Rowntree CI (1983) The relation of multiple hippocampal theta cell discharge rates to slow wave theta frequency. Physiol Behav 31:111-117.

Burgess AP, Gruzelier JH (1997) Short duration synchronization of human theta rhythm during recognition memory. NeuroReport 8:1039-1042.

Buzsaki G (1984) Feed-forward inhibition in the hippocampal formation. Prog Neurobiol 22:131-153.

Christian EP, Deadwyler SA (1986) Behavioral functions and hippocampal cell types: evidence for two nonoverlapping populations in the rat. J Neurophysiol 55:331-348.

Csicsvari J, Hirase H, Czurko A, Mamiya A, Buzsaki G (1999) Oscillatory coupling of hippocampal pyramidal cells and interneurons in the behaving rat. J Neurosci 19:274-287.

Deadwyler SA, Hampson RE (1998) Evidence for anatomic specificity of spatial representation in hippocampus. Soc Neurosci Abstr 24:1908.

Deadwyler SA, Bunn T, Hampson RE (1996) Hippocampal ensemble activity during spatial delayed-nonmatch-to-sample performance in rats. J Neurosci 16:354-372.

Eichenbaum H, Kuperstein M, Fagan A, Nagode J (1987) Cue-sampling and goal-approach correlates of hippocampal unit activity in rats performing an odor-discrimination task. J Neurosci 7:716-732.
Eichenbaum H, Schoenbaum G, Young B, Bunsey M (1996) Functional organization of the hippocampal memory system. Proc Natl Acad Sci USA 93:13500-13507.

Foster TC, Christian EP, Hampson RE, Campbell KA, Deadwyler SA (1987) Sequential dependencies regulate sensory evoked responses of single units in the rat hippocampus. Brain Res 408:86-96.

Fox SE, Ranck JB (1975) Localization and anatomical identification of theta and complex spike cells in dorsal hippocampal formation of rats. Exp Neurol 49:299-313.

Fox SE, Ranck JB (1981) Electrophysiological characteristics of hippocampal complex-spike cells and theta cells. Exp Brain Res 41:399-410.

Freund TF, Buzsaki G (1996) Interneurons of the hippocampus. Hippocampus $6: 347-470$.

Givens B, Olton DS (1994) Local modulation of basal forebrain: effects on working and reference memory. J Neurosci 14:3578-3587.

Hampson RE, Deadwyler SA (1996) Ensemble codes involving hippocampal neurons are at risk during delayed performance tests. Proc Natl Acad Sci USA 93:13487-13493.

Hampson RE, Jarrard LE, Deadwyler SA (1999) Effects of ibotenate hippocampal and extrahippocampal destruction on delayed-match and -nonmatch-to-sample behavior in rats. J Neurosci 19:1492-1507.

Hess US, Lynch G, Gall CM (1995) Regional patterns of c-fos mRNA expression in rat hippocampus following exploration of a novel environment versus performance of a well-learned discrimination. J Neurosci 15:7796-7809.

Jung MW, McNaughton BL (1993) Spatial selectivity of unit activity in the hippocampal granular layer. Hippocampus 3:165-182.

Kubie JL, Muller RU, Bostock E (1990) Spatial firing properties of hippocampal theta cells. J Neurosci 10:1110-1123.

McEchron MD, Disterhoft JF (1997) Sequence of single neuron changes in CA1 hippocampus of rabbits during acquisition of trace eyeblink conditioned responses. J Neurophysiol 78:1030-1044.

McNaughton BL, Barnes CA, O'Keefe J (1983a) The contributions of position, direction, and velocity to single unit activity in the hippocampus of freely moving rats. Exp Brain Res 52:41-49.

McNaughton BL, O'Keefe J, Barnes CA (1983b) The stereotrode: a new technique for simultaneous isolation of several single units in the central nervous system from multiple unit records. J Neurosci Methods 8:391-397.

Mizumori SJY, McNaughton BL, Barnes CA (1989) A comparison of supramammillary and medial septal influences on hippocampal field potentials and single-unit activity. J Neurophysiol 61:15-31.

Mumby DG, Pinel JPJ (1994) Rhinal cortex lesions and object recognition in rats. Behav Neurosci 108:11-18.

Murray EA, Mishkin M (1998) Object recognition and location memory in monkeys with excitotoxic lesions of the amygdala and hippocampus. J Neurosci 18:6568-6582.

O'Keefe J (1976) Place units in the hippocampus of the freely moving rat. Exp Neurol 51:78-109.

O'Keefe J, Nadel L (1978) The hippocampus as a cognitive map. London: Oxford UP.

Otto T, Eichenbaum H (1992) Neuronal activity in the hippocampus during delayed non-match to sample performance in rats: evidence for 
hippocampal processing in recognition memory. Hippocampus 2:323-334.

Ranck JB (1973) Studies on single neurons in dorsal hippocampal formation and septum in unrestrained rats. Part I. Behavioral correlates and firing repertoires. Exp Neurol 41:461-555.

Rencher AC (1995) Methods of multivariate analysis. New York: Wiley.

Rivas J, Gaztelu JM, Garcia-Austt E (1996) Changes in hippocampal cell discharge patterns and theta rhythm spectral properties as a function of walking velocity in the guinea pig. Exp Brain Res 108:113-118.

Rolls ET, Cahusac PM, Feigenbaum JD, Miyashita Y (1993) Responses of single neurons in the hippocampus of the macaque related to recognition memory. Exp Brain Res 93:299-306.

Sakurai Y (1994) Involvement of auditory cortical and hippocampal neurons in auditory working memory and reference memory in the rat. J Neurosci 14:2606-2623.

Stäubli UV, Xu FB (1995) Effects of 5-HT3 receptor antagonism on hippocampal theta rhythm, memory, and LTP induction in the freely moving rat. J Neurosci 15:2445-2452.

Suzuki WA (1996) The anatomy, physiology and functions of the perirhinal cortex. Curr Opin Neurobiol 6:179-186.

Wiebe SP, Stäubli UV (1999) Dynamic filtering of recognition memory codes in the hippocampus. J Neurosci 19:10562-10574.

Winson J (1978) Loss of hippocampal theta rhythm results in spatial memory deficit in the rat. Science 201:160-163.

Wood ER, Mumby DG, Pinel JP, Phillips AG (1993) Impaired object recognition memory in rats following ischemia-induced damage to the hippocampus. Behav Neurosci 107:51-62.

Wood ER, Dudchenko PA, Eichenbaum H (1999) The global record of memory in hippocampal neuronal activity. Nature 397:613-616.

Young BJ, Otto T, Fox GD, Eichenbaum H (1997) Memory representation within the parahippocampal region. J Neurosci 17:5183-5195. 